20

\title{
Ультрафиолетовая люминесценция и светорассеяние систем фотодитазина с альгинатом натрия, поли-N-винилпирролидоном и триптофаном*
}

\author{
(С) Л.В. Беловолова ${ }^{1}$, М.В. Глушков ${ }^{1}$, Н.А. Аксенова ${ }^{2}$, А.Б. Соловьева ${ }^{2}$, О.В. Хасанова ${ }^{2}$ \\ ${ }^{1}$ Институт общей физики им. А.М. Прохорова РАН, \\ 119991 Москва, Россия \\ ${ }^{2}$ Институт химической фризики им. Н.Н. Семенова РАН, \\ 119991 Москва, Россия \\ e-mail: est123321@mail.ru
}

Поступила в редакцию 28.12.2018 г.

В окончательной редакции 19.02.2019 г.

Принята к публикации 26.02.2019 г.

В рамках исследования полимерных систем на основе хлоринового фотосенсибилизатора фотодитазина (PD) для фотодинамической терапии изучены спектры флуоресценции и релеевского светорассеяния при возбуждении на длинах волн $\lambda_{\mathrm{ex}}=260,280,400$ и $450 \mathrm{~nm}$. В качестве полимера использовали нетоксичный водорастворимый поли-N-винилпирролидон (PVP) и растительный полисахарид альгинат натрия (SA). Данные двойной системы PD-SA отличаются вариабельностью характеристик в зависимости от условий приготовления, в то время как в тройном комплексе PD-SA-PVP наблюдается благоприятное взаимное влияние двух полимеров SA и PVP на молекулу PD, обусловленное созданием локального микроокружения активного центра PD с повышенной полярностью. Показано, что введение триптофана (Trp), используемого в качестве субстрата в модельных процессах фотоокисления при тестировании эффективности фотосенсибилизаторов в генерации синглетного кислорода, существенно не меняет параметры флуоресценции комплекса PD-SA-PVP.

DOI: $10.21883 /$ OS.2019.06.47773.54-19

\section{Введение}

В настоящее время фотодинамическая терапия (PDT) является эффективным методом лечения заболеваний опухолевой и неопухолевой природы. Несмотря на большое число исследований, посвященных детальному анализу отдельных стадий процесса на биохимическом и модельном уровнях, механизм PDT до конца не изучен. Как следует из литературных данных, существуют две основные теории, объясняющие механизм противоопухолевого действия PDT [1-5]. В реакциях первого типа молекула фотосенсибилизатора (PS), поглотив квант света, из основного состояния PS переходит сначала в возбужденное синглетное ${ }^{1} \mathrm{PS}^{*}$, затем в триплетное состояние ${ }^{3} \mathrm{PS}^{*}[5,6]$. Происходит непосредственное взаимодействие ${ }^{3} \mathrm{PS}^{*}$ с молекулами окружения, в частности с водой (отрыв электрона или непосредственно атомов водорода), что ведет к образованию свободных радикалов, которые затем реагируют с молекулярным кислородом и дают сложную смесь высокоактивных продуктов. В реакциях второго типа происходит перенос энергии от ${ }^{3} \mathrm{PS}^{*}$ к молекулам кислорода и генерация синглетного $\left({ }^{1} \mathrm{O}_{2}^{*}\right)$ кислорода, являющегося активным окислителем.

\footnotetext{
* The 22nd Annual Conference Saratov Fall Meeting 2018 (SFM'18): VI International Symposium „Optics and Biophotonics“ and XXII International School for Junior Scientists and Students on Optics, Laser Physics \& Biophotonics, September 24-29, 2018, Saratov, Russia. https://www.sgu.ru/structure/fiz/saratov-fall-meeting/previousconferences/saratov-fall-meeting-2018
}

Появление ${ }^{1} \mathrm{O}_{2}^{*}$ дает начало сложной системе взаимопревращений активных форм кислорода и воды (АФК), важнейшими из которых являются анион-радикал супероксида $\left(\mathrm{O}_{2}^{-\bullet}\right)$ и гидроксильный радикал $\left(\mathrm{OH}^{\bullet}\right)$, а также перекись водорода $\left(\mathrm{H}_{2} \mathrm{O}_{2}\right)$ [7-9]. При взаимодействии ${ }^{1} \mathrm{O}_{2}^{*}$ с двойными связями органических молекул образуются органические пероксиды ROOR ${ }^{1}$, способные накапливаться и затем разлагаться с образованием вторичных активных соединений. При использовании порфиринов в качестве PS первичным действующим агентом обычно является синглетный кислород [5,10,11].

Известно, что в результате возбуждения кислорода в биологических системах и водных средах могут возникать долгоживущие колебательные и релаксационные процессы, обусловленные накоплением и распадом $\mathrm{H}_{2} \mathrm{O}_{2}$ и органических пероксидов [6-9,12-14], в результате чего в системе появляются и исчезают различные виды АФК. На конечном этапе фотодинамического воздействия оба типа фотохимических реакций приводят к деструктивным процессам в жизненно важных структурах клеток и их гибели $[14,15]$.

Гидрофобная природа большинства PS приводит к образованию их агрегатов в водной среде, которые не только ограничивают доставку PS к опухолевым клеткам, но также могут приводить к самотушению PS в возбужденном состоянии, что снижает образование ${ }^{1} \mathrm{O}_{2}^{*}$ [16]. Одним из путей решения таких проблем, может служить комплексообразование PS с нетоксичными 
водорастворимыми полимерами, которое, как было показано в [16], может не только снижать агрегированность $\mathrm{PS}$, но и приводить к увеличению фотокаталитической активности PS. Поскольку полимерные компоненты PVP и SA, вводимые в систему с исходным раствором фотодитазина, могут сами вступать в реакции с ${ }^{1} \mathrm{O}_{2}^{*}$ и вовлекаться в иные процессы с участием АФК, одна из задач данной работы состоит в рассмотрении возможности участия АФК, генерируемых порфиринсодержащими полимерными системами, в процессах фотосенсибилизированного окисления триптофана.

В модельных экспериментах, направленных на выбор оптимальных порфиринсодержащих полимерных систем, активность PS (фотодитазина (PD)) в комплекcax с полимерами PVP и SA [13] определялась по уменьшению поглощения в полосе $\operatorname{Trp}\left(\lambda_{\mathrm{obs}}=280 \mathrm{~nm}\right)$ в результате его окисления синглетным кислородом при возбуждении PD при $\lambda_{\mathrm{obs}}=400 \mathrm{~nm}$ (полоса Cope) [17]. Присутствие Trp в изучаемой системе само по себе способно оказывать влияние на структуру, динамику и активность комплексов, поэтому изучены также возможные взаимодействия триптофана с PS и вводимыми полимерами.

Спектры флуоресценции и светорассеяния порфиринсодержащих двух- (PD-SA, PD-PVP) и трехкомпонентных (PD-SA-PVP) полимерных композиций изучали при возбуждении на длинах волн $\lambda_{\mathrm{ex}} \sim 260,280,400$ и $450 \mathrm{~nm}$. Выбор этих длин волн возбуждения позволил сравнить особенности систем на длине волны проведения PDT $(400 \mathrm{~nm})$, в полосе поглощения $\operatorname{Trp}(280 \mathrm{~nm})$ и в области поглощения $\mathrm{O}_{2}^{-\bullet}(260 \mathrm{~nm})$, а также вне полос существенного поглощения всех хромофоров $(450 \mathrm{~nm})$.

\section{Экспериментальная часть}

В работе использовали (рис. 1) PS N-метил-диD-глюкаминовая соль хлорина е6 (фотодитазин, PD) (Вета-Гранд, Россия), амфифильный полимер - полиN-винилпирролидон (PVP) $\left(M_{w} 40000\right.$, Dr. Theodor Schuchardt, Германия), полисахарид - альгинат натрия (SA) $\left(M_{w}(80000-100000)\right.$, Sigma Aldrich, США), триптофан (Trp) (Реахим, Россия).

\section{Приготовление образцов}

К водному раствору PD (5M/1) добавляли водные растворы полимеров - PVP и SA, затем раствор субстрата - $\operatorname{Trp}(100 \mu \mathrm{M} / 1)$. Концентрация вводимых полимеров: PVP $(100 \mu \mathrm{M} / 1)$ и $\mathrm{SA}(10 \mu \mathrm{M} / 1)$. Водный раствор перемешивали в течение трех минут, после чего регистрировали спектры флуоресценции и светорассеяния.

\section{Запись спектров}

Спектры флуоресценции и светорассеяния записывали с помощью модернизированного спектрально-измери- тельного комплекса СДЛ-2 (ЛОМО, Россия) в режиме счета фотонов. В этой установке свет ксеноновой лампы мощностью 150 Вт пропускается через монохроматор МДР-12 и системой линз фокусируется в объеме кюветы $\left(2 \mathrm{~cm}^{3}\right)$ на площадку $\sim 2 \mathrm{~mm}^{2}$. Флуоресценцию и светорассеяние регистрировали под прямым углом к возбуждающему свету с использованием второго монохроматора МДР-23. Условия записи поддерживали постоянными. Запись спектров проводили при комнатной температуре без коррекции спектров на чувствительность аппаратуры. Относительная ошибка измерения интенсивности светорассеяния и флуоресценции не превышала $10 \%$.

\section{Результаты и обсуждение}

При $\lambda_{\mathrm{ex}}=400 \mathrm{~nm}$ возбуждается порфириновая группировка $\mathrm{PD}$, флуоресценция которой проявлена в области 650-670 nm (рис. 2). Тушение триплетного состояния ${ }^{3} \mathrm{PD}^{*}$ растворенным кислородом приводит к образованию ${ }^{1} \mathrm{O}_{2}^{*}$, который является, по крайней мере, первичным агентом, обусловливающим биологическую активность исследуемых систем [5,10,11]:

$$
\begin{gathered}
\mathrm{PD}+h v \rightarrow{ }^{3} \mathrm{PD}^{*}, \\
{ }^{3} \mathrm{PD}^{*}+{ }^{3} \mathrm{O}_{2} \rightarrow{ }^{1} \mathrm{PD}+{ }^{1} \mathrm{O}_{2}^{*} .
\end{gathered}
$$

При постоянной концентрации PD $(5 \mu \mathrm{M} / 1)$ (в насыщенных воздухом водных средах содержание кислорода $\sim 0.2 \mathrm{mM} / \mathrm{l}$ ) скорость образования синглетного кислорода пропорциональна содержанию возбужденных молекул $\mathrm{PD}^{*}$ и, следовательно, интенсивности флуоресценции, наблюдаемой в области 650-680 nm. Однако следует отметить, что измеряемые значения констант скоростей реакций исследуемых систем определяются не только содержанием ${ }^{1} \mathrm{O}_{2}^{*}$, но и параметрами микроокружения активного центра PS и эффективностью столкновения ${ }^{1} \mathrm{O}_{2}^{*}$ с реакционными группами молекулы Trp. При связывании PS и Trp с разными полимерами эти характеристики могут быть различными. На рис. 2, $a, b$ представлены спектры флуоресценции комплексов в присутствии и в отсутствие Trp соответственно. Из рисунка можно видеть, что в присутствии Trp добавление SA существенно снижает интенсивность флуоресценции PD. Без $\operatorname{Trp}$ (рис. 2,b) влияние SA на спектр флуоресценции PD существенно меньше. Комплексообразование PD с PVP независимо от присутствия Trp приводит к сдвигу спектра флуоресценции в красную область. При этом в отсутствие Trp наблюдается появление плеча в области 640-650 nm, что указывает на появление дополнительного продукта или состояния PD. Поскольку в системах PD-PVP и PD-SA-PVP с Trp это плечо отсутствует, то можно заключить, что Тrр связывает или устраняет этот продукт или состояние PD.

В системе с Trp высокая интенсивность флуоресценции $\mathrm{PD}$ с максимумом около $670 \mathrm{~nm}$ наблюдается 


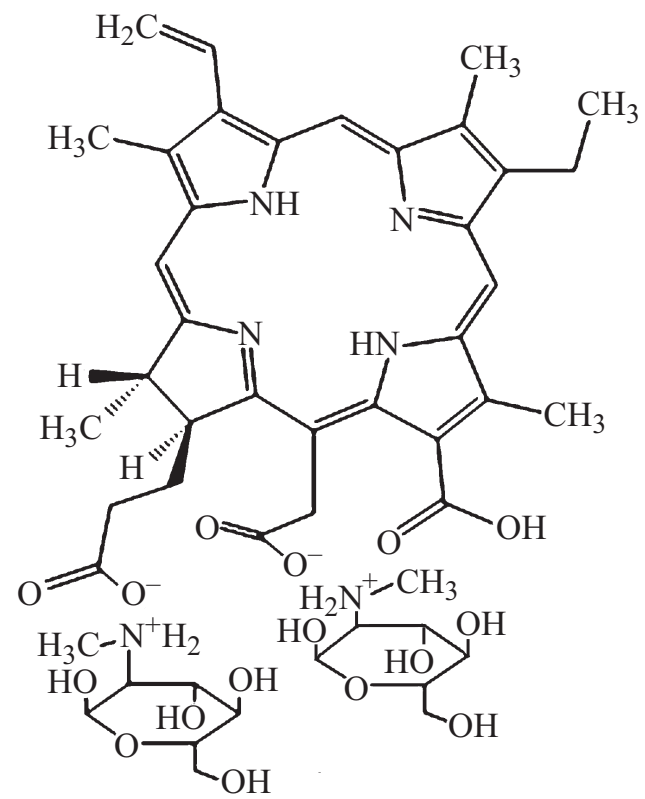

N-methyl-di-D-glucamine salt of chlorin e6 (photoditazin, PD)<smiles>N[C@@H](Cc1c[nH]c2ccccc12)C(=O)O</smiles><smiles>CCCC(CC)N(C)C=O</smiles>
(PVP)

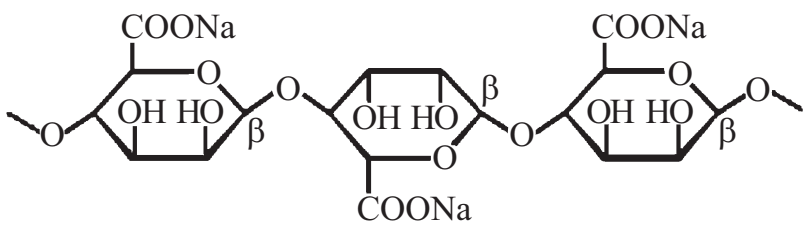

sodium alginate $(\mathrm{SA})$

Рис. 1. Структурные формулы использованных соединений.
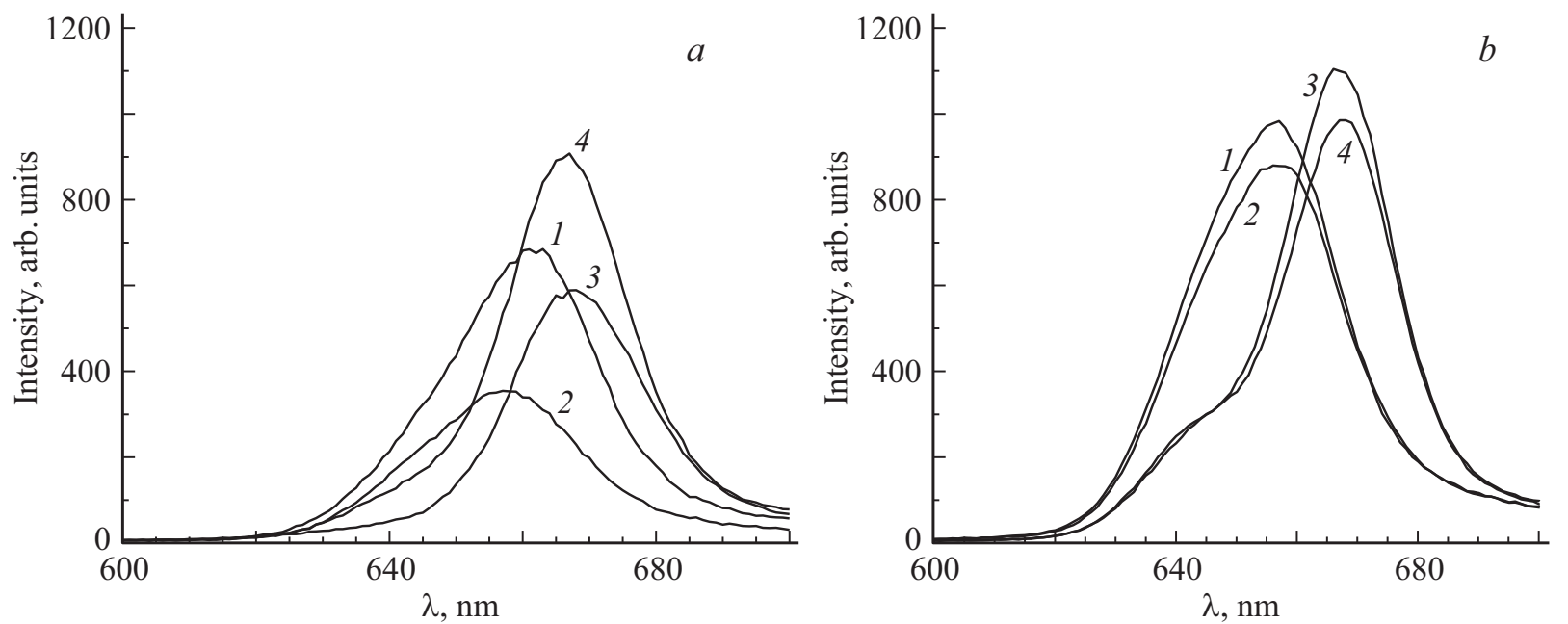

Рис. 2. Спектры флуоресценции при $\lambda_{\mathrm{ex}}=400 \mathrm{~nm}: 1-\mathrm{PD}(5 \mu \mathrm{M} / 1), 2-\mathrm{PD}-\mathrm{SA}(10 \mu \mathrm{M} / 1), 3-\mathrm{PD}-\mathrm{PVP}(100 \mu \mathrm{M} / 1), 4-$ PD-SA-PVP ; в присутствии $(a)$ и в отсутствие $(b) \operatorname{Trp}(100 \mu \mathrm{M} / 1)$.

для комплекса PD-SA-PVP, что указывает на наиболее высокую биологическую активность этого комплекса по сравнению с другими системами (PD, PD-PVP, PD-SA). Этот факт подтверждается результатами кинетических измерений. Обнаружено, что фотосенсибилизирующая активность PS, которую характеризует эффективная константа скорости окисления Trp, возрастает по сравнению с фотокаталитической активностью исходного раствора фотодитазина (при относительной ошибке в определении константы скорости 10\%) в PD-PVP в 1.5 раза, в комплексе PD-SA в 1.1 раза, а в тройных системах PD-PVP-SA в 2 раза. Можно говорить о взаимном влиянии PVP и SA на активность PD. Сдвиг максимума пика флуоресценции $\mathrm{PD}$ в тройной системе PD-PVP-SA в сторону длинных волн свидетельствует об увеличении полярности локального окружения хромофора PD по сравнению с исходным раствором PD и двойным комплексом PD-SA [18]. Таким образом, спектр флуоресценции тройного комплекса PD-SA-PVP (рис. 2) указывает на симбиотическое влияние SA и PVP на состояние хромофора. В тройном комплекce PD-SA-PVP присутствие Trp существенного влияния на флуоресценцию с максимумом $\sim 670 \mathrm{~nm}$ не оказывает. 

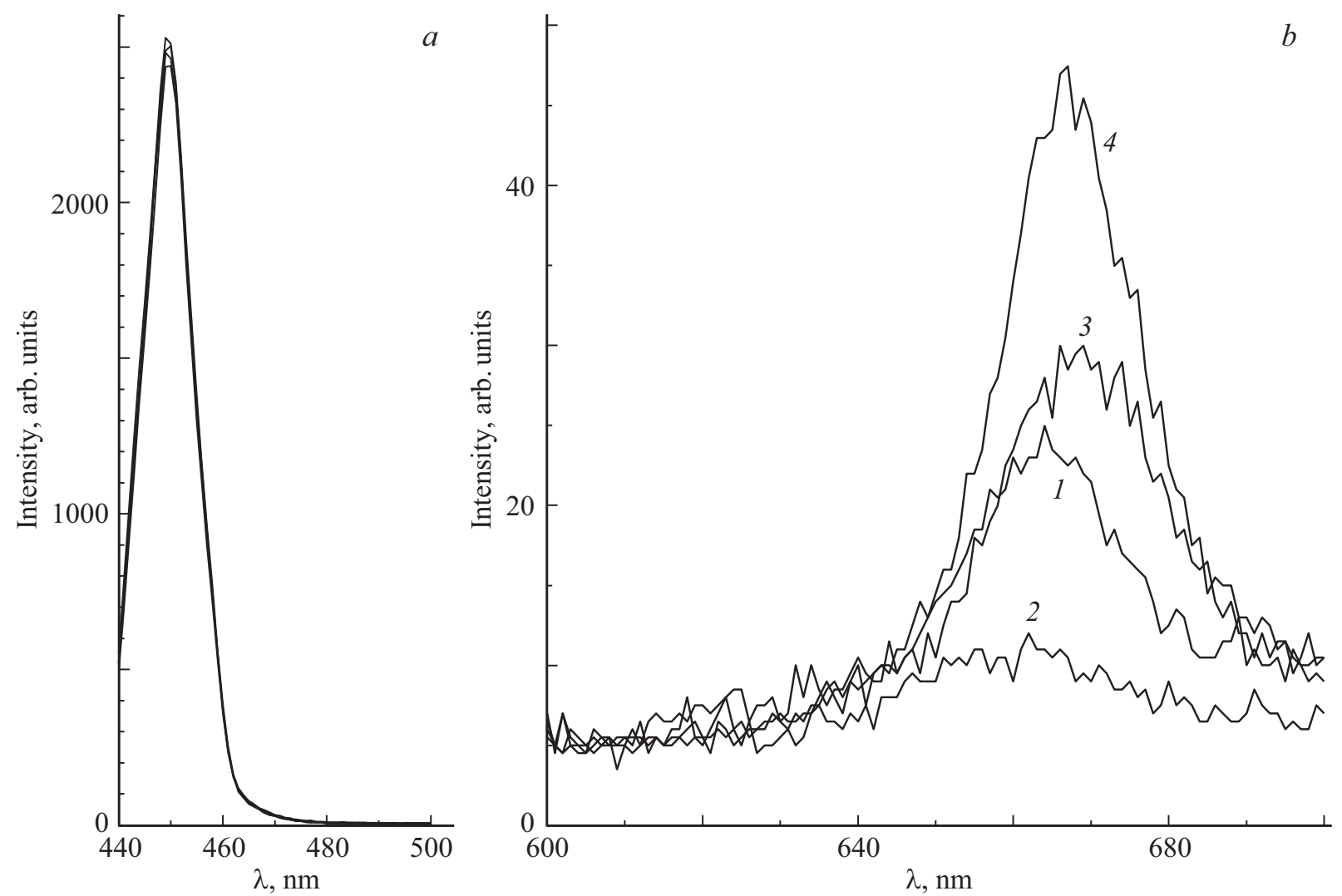

Рис. 3. Спектры светорассеяния $(a)$ и флуоресценции $(b)$ при $\lambda_{\mathrm{ex}}=450 \mathrm{~nm}$ в присутствии $\operatorname{Trp}(100 \mu \mathrm{M} / 1): 1-\mathrm{PD}(5 \mu \mathrm{M} / 1), 2-$ PD-SA $(10 \mu \mathrm{M} / 1), 3$ - PD-PVP $(100 \mu \mathrm{M} / 1), 4$ - PD-SA-PVP.

Характер спектров флуоресценции PD в диапазоне длин волн $600-700 \mathrm{~nm}$ в присутствии триптофана в исследуемых системах практически не зависит от длины волны возбуждения света в диапазоне $260-450 \mathrm{~nm}$, хотя их интенсивность меняется существенно (рис. $2, a, 3, b$, $5, c)$. Зависимость интенсивности спектров светорассеяния и флуоресценции, наблюдаемых под прямым углом к пучку возбуждающего света, от длины волны возбуждения позволяет судить о характере взаимодействия рассеивающих центров с возбуждающим светом. При $\lambda_{\text {ex }}=450 \mathrm{~nm}$ все системы рассеивают одинаково (рис. 3 ), но при $\lambda_{\text {ex }}<400 \mathrm{~nm}$ интенсивность рассеяния систем с PVP значительно превышает интенсивность рассеяния других систем (рис. $4,5, a)$.

Анализ спектров поглощения исследуемых систем показал, что введение полимера PVP в раствор PD существенно не изменяет оптическую плотность в областях возбуждения $260-280 \mathrm{~nm}(\Delta D \leq 0.05)$, в то время как интенсивность рассеяния в разных системах различается существенно (рис. 4,5). Из спектров светорассеяния (рис. 4, a) можно заключить, что при $\lambda_{\mathrm{ex}} \sim 280 \mathrm{~nm}$ PVP влияет на характер неоднородностей системы на масштабах, сравнимых с длиной волны возбуждения. Повидимому, эти особенности связаны с увеличением размеров комплексов PD-PVP и PD-SA-PVP по сравнению с $\mathrm{PD}$ и PD-SA. Однако интенсивность рассеяния двойной системой PD-PVP в $\sim 2$ раза выше интенсивности рассеяния PD-SA-PVP (рис. 4, $a$ ). По-видимому, это связано с уплотнением структурной матрицы вокруг активного центра PD в тройных системах PD-SA-PVP.

Интенсивность Trр-флуоресценции максимальна в отсутствие полимеров (рис. 4, $b$ ), но существенно снижается в присутствии SA и PVP. Эти факты указывают на изменение состояния $\operatorname{Trp}$ в разных фотодитазинсодержащих полимерных системах. Об этом же свидетельствуют спектры Trp флуоресценции при $\lambda_{\mathrm{ex}}=260 \mathrm{~nm}$ (рис. 5).

Характер спектров флуоресценции систем Тrр при $\lambda_{\mathrm{ex}}=260 \mathrm{~nm}$ (рис. 5) близок к показанному на рис. 4 для $\lambda_{\mathrm{ex}}=280 \mathrm{~nm}$, за исключением высокой интенсивности флуоресценции и рассеяния системы PD-SA-PVP. Кроме того, при $\lambda_{\mathrm{ex}}=260 \mathrm{~nm}$ в тройной системе PD-SA-PVP четко выражен дополнительный пик флуоресценции с максимумом около $425 \mathrm{~nm}$ (рис. 5,c), отсутствующий в PD-SA. B PD и PD-PVP этот пик проявлен в виде ступеньки. Его яркое выражение в PD-SA-PVP свидетельствует об отличии тройной системы от других исследуемых систем. При $\lambda_{\mathrm{ex}}=260 \mathrm{~nm}$ спектры флуоресценции с максимумами в области $420-450 \mathrm{~nm}$ имеют многие производные карбонильных соединений [19]. В частности, они наблюдаются в аптечной перекиси водорода и при перекисном окислении органических соединений $[19,20]$. 

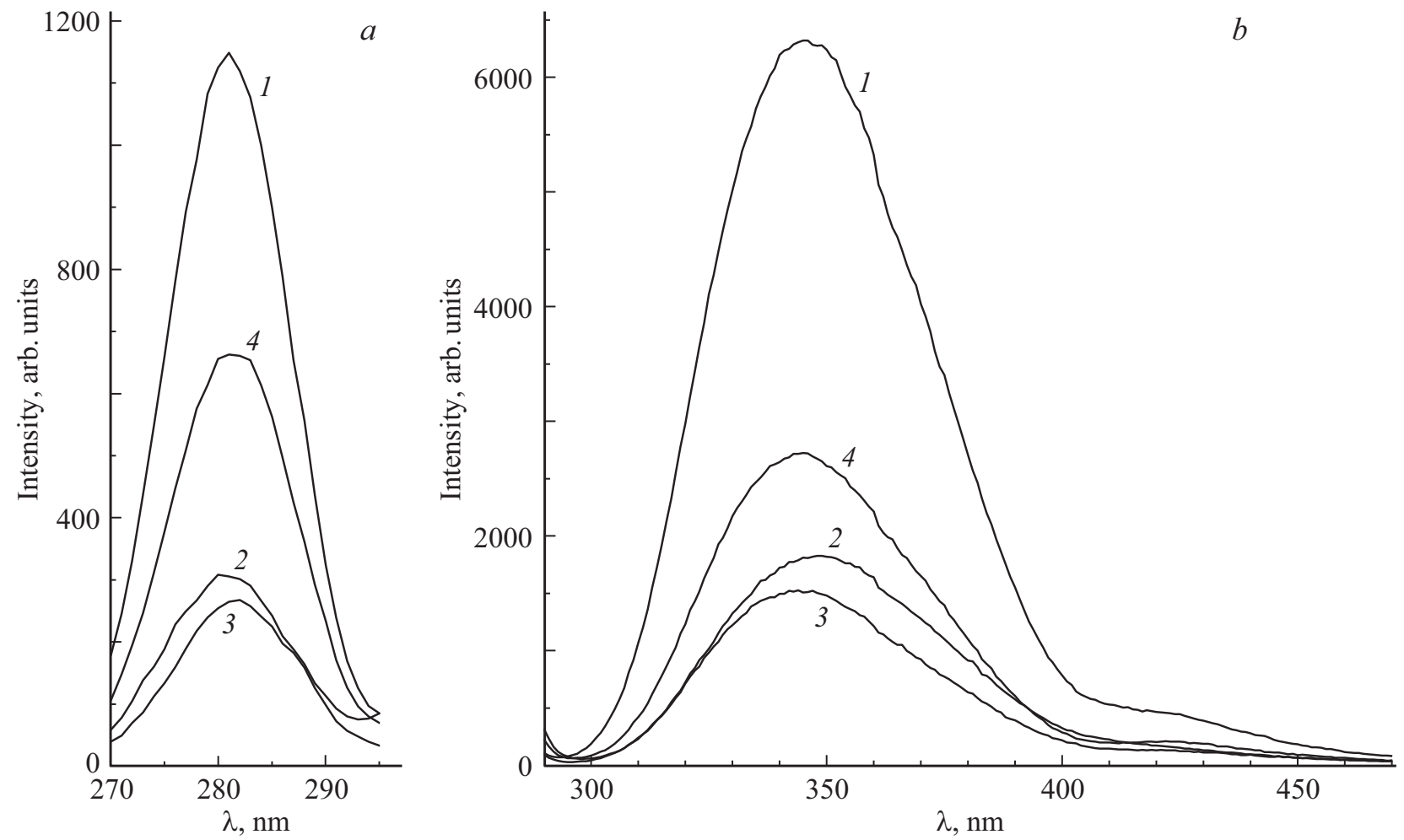

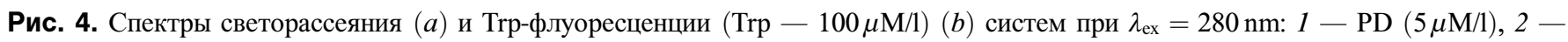
PD-SA $(10 \mu \mathrm{M} / 1), 3$ - PVP $(100 \mu \mathrm{M} / 1), 4$ - PD-SA-PVP.
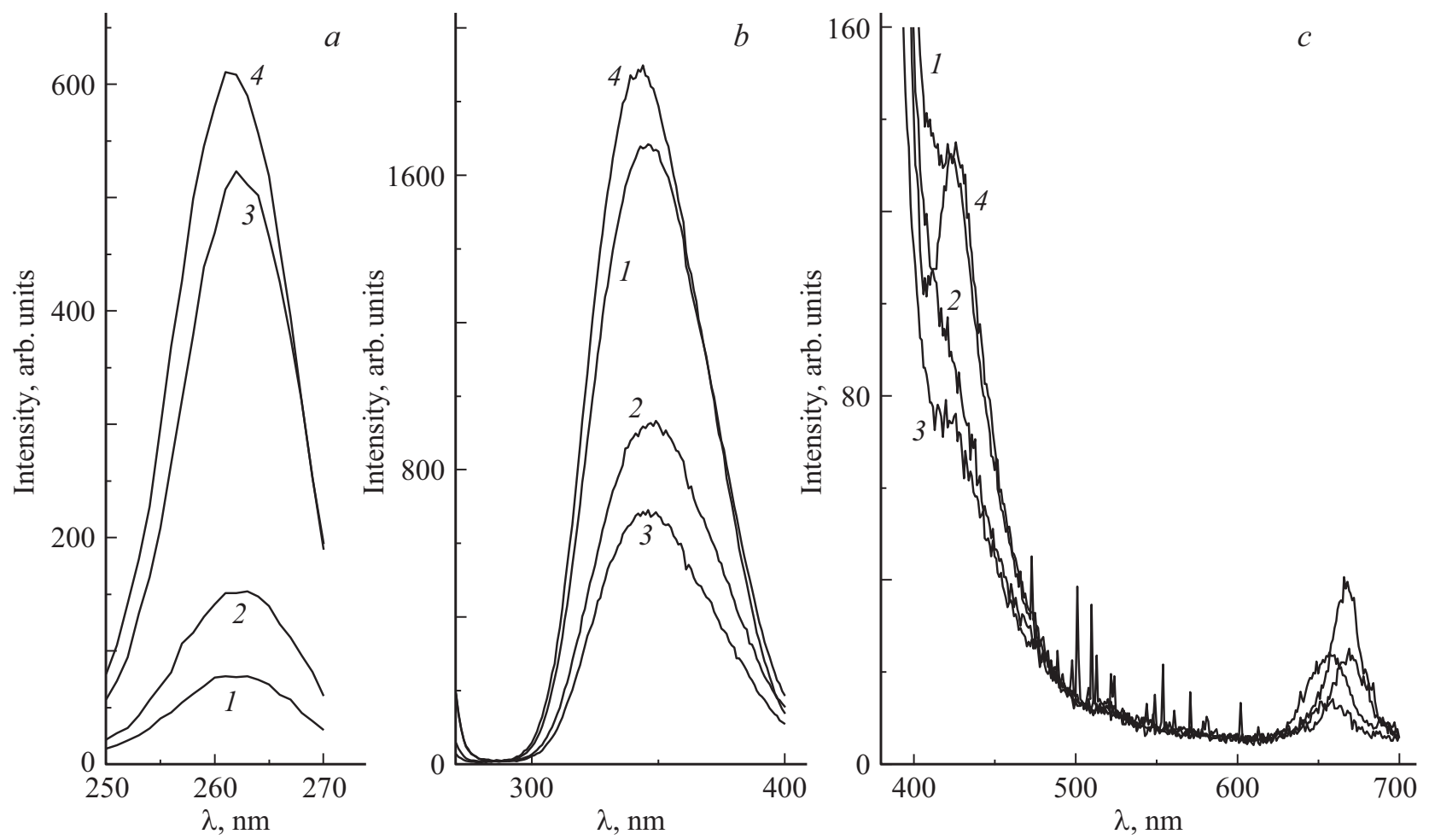

Рис. 5. Спектры светорассеяния $(a)$, флуоресценции $(b, c)$ систем с $\operatorname{Trp}(100 \mu \mathrm{M} / 1)$ при $\lambda_{\mathrm{ex}}=260 \mathrm{~nm}: 1-\mathrm{PD}(5 \mu \mathrm{M} / 1), 2-\mathrm{PD}-\mathrm{SA}$ $(10 \mu \mathrm{M} / 1), 3$ - PD-PVP $(100 \mu \mathrm{M} / 1), 4$ - PD-SA-PVP. 


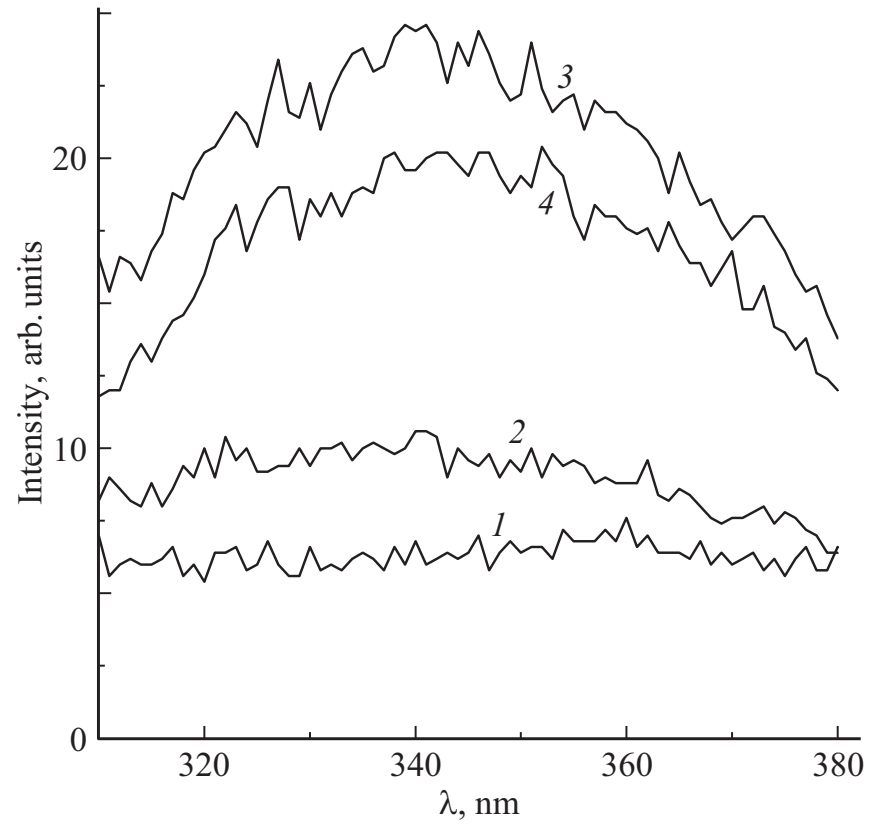

Рис. 6. Спектры флуоресценции при $\lambda_{\mathrm{ex}}=260 \mathrm{~nm}$ в отсутствие Trp (в образце PD (1) сигнал мало отличается от нулевой линии): 1 - PD $(5 \mu \mathrm{M} / 1), 2-\mathrm{PD}-\mathrm{SA}(10 \mu \mathrm{M} / 1), 3-$ PD-PVP $(100 \mu \mathrm{M} / 1), 4$ - PD-SA-PVP.

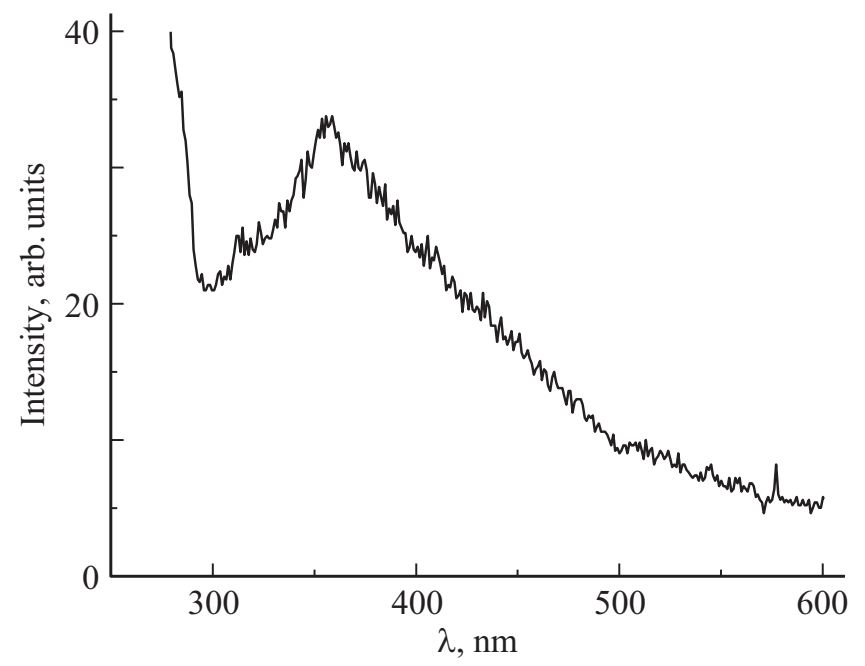

Рис. 7. Спектр флуоресценции PVP $(100 \mu \mathrm{M} / 1)$ при $\lambda_{\mathrm{ex}}=260 \mathrm{~nm}$.

Спектры флуоресценции систем PD-PVP и PD-SA-PVP при $\lambda_{\mathrm{ex}}=260 \mathrm{~nm}$ в отсутствие $\operatorname{Trp~(рис.~6)~также~}$ указывают на возникновение АФК в реакционных смесях с PVP. Они проявляются в виде слабого широкого сигнала флуоресценции с максимумом в области 340-350 nm. Спектр флуоресценции PVP с максимумом около 350-360 nm (без коррекции на чувствительность установки, рис. 7) при $\lambda_{\mathrm{ex}}=260 \mathrm{~nm}$ свидетельствует о появлении $\mathrm{O}_{2}^{-\bullet}$ и связанных с ним процессах в водном растворе PVP [20]. Поскольку такие сигналы проявля- ются в системах, содержащих органические пероксиды, можно полагать, что процессы образования перекисных соединений имеют место и в используемых системах.

Следует отметить, что в настоящее время спектры АФК в водных средах исследованы слабо из-за высокой активности, низких концентраций и малого времени жизни этих частиц. [7-9,19-21]. Концентрация наиболее стабильного и легко уловимого вида АФК $-\mathrm{H}_{2} \mathrm{O}_{2}$ в природных водах и клетках живых организмов в обычных условиях составляет $\sim 0.1 \mu \mathrm{M} / 1$ [21]. Концентрация радикальных форм АФК обычно на порядки ниже. Однако в определенные моменты нормальной жизнедеятельности клеток концентрация АФК может повышаться, что можно регистрировать по повышению содержания пероксидов [7-9]. При этом могут возникать периодические или квазипериодические изменения интенсивности свечения водных и биологических систем, обусловленные накоплением и последующим разложением пероксидов на радикалы [7-9]. Излучения обычно вызваны рекомбинациями радикалов, образующихся при распаде $\mathrm{H}_{2} \mathrm{O}_{2}$ и органических пероксидов и вторичными реакциями с их участием.

\section{Заключение}

Из полученных данных можно сделать вывод, что на длине волны $\lambda_{\mathrm{ex}}=400 \mathrm{~nm}$, при которой происходит возбуждение порфириновой группировки молекулы $\mathrm{PD}$, можно наблюдать рост интенсивности и сдвиги полос флуоресценции при добавлении полимеров (PVP и SA) по сравнению со спектром для исходного фотодитазина. В спектрах флуоресценции в присутствии триптофана при возбуждении светом с $\lambda_{\mathrm{ex}}=400 \mathrm{~nm}$ (рис. 2) для тройной системы PD-SA-PVP интенсивность флуоресценции $\mathrm{PD}$ выше в $\sim 1.3$ раза по сравнению с интенсивностью полосы исходного $\mathrm{PD}$, в $\sim 1.6$ раз выше, чем для двойной системы PD-PVP, и в $\sim 3$ раза выше, чем для системы PD-SA. Помимо проявляемого повышения интенсивности флуоресценции в системе PD-SA-PVP в присутствии и в отсутствие Trp в полосах флуоресценции зафиксированы батохромные сдвиги (на $\sim 5 \mathrm{~nm}$ ) относительно полос в спектрах чистого фотодитазина. Очевидно, такое повышение интенсивности и сдвиг полос флуоресценции в тройной системе PD-SA-PVP связаны с взаимным влиянием PVP и SA на молекулу PD. Это приводит к уплотнению структурной матрицы вокруг активного центра порфирина и созданию благоприятного локального микроокружения с повышенной полярностью. Интересен и тот факт, что значительно меняется спектр флуоресценции именно двойной системы PD-SA в присутствии и в отсутствие триптофана. Присутствие триптофана оказывает влияние на флуоресценцию PD в системе PD-SA в большей степени по сравнению с другими системами.

Наибольшая интенсивность светорассеяния при возбуждении системы светом $\lambda \sim 280 \mathrm{~nm}$ (полоса погло- 
щения триптофана) наблюдается для систем с PVP, причем в тройной системе PD-SA-PVP интенсивность рассеяния вдвое ниже, чем в PD-PVP (рис. 4). Такое поведение системы PD-SA-PVP, очевидно, связано с образованием более плотных частиц меньшего размера по сравнению с двойными системами PD-PVP(SA). Повидимому, PVP выступает в роли связующего агента между SA и $\mathrm{PD}$, что, очевидно, приводит к большей дезагрегации молекул PD в тройных системах, нежели в двойных PD-PVP и PD-SA.

Особенности спектров флуоресценции систем свидетельствуют о возможном участии в исследуемых процесcax не только ${ }^{1} \mathrm{O}_{2}^{*}$, генерируемого при возбуждении PD в полосе Cope, но и других видов АФК, появляющихся в данных системах при окислении синглетным кислородом и ультрафиолетовом освещении. Использование Trp в качестве субстрата в модельных процессах фотоокисления при тестировании эффективности фотосенсибилизаторов в генерации синглетного кислорода существенно не меняет параметры флуоресценции комплекса PD-SA-PVP. Однако полученные спектры флуоресценции и светорассеяния свидетельствуют о наличии некоторого химического сродства триптофана к фрагментам вводимых полимеров, около которых, по-видимому, координируются молекулы PS. Эти наблюдения требуют дальнейшего исследования.

\section{Финансирование работы}

Работа выполнена при поддержке Российского фонда фундаментальных исследований. Грант РФФИ 17-0200294.

\section{Конфликт интересов}

Авторы заявляют, что у них нет конфликта интересов.

\section{Список литературы}

[1] Rosenkranz A.A., Jans D.A., Sobolev A.S. // Immun. Cell Biol. 2000. V. 78. P. 452

[2] Улащик В.С. // Физиотерапия, бальнеология и реабилитация. 2013. № 1. С. 36.

[3] Узденский А.Б. // Биофизика. 2016. Т. 61. № 3. С. 547.

[4] Акопов А.Л., Казаков Н.В., Русанов А.А., Карлсон А. // Фотодинамическая терапия и фотодиагностика. 2015. № 2. C. 9.

[5] Красновский А.А. (мл.) // Проблемы регуляции в биологических системах. / Под ред. Рубина А.Б. М., Ижевск: НИЦ „Регулярная и хаотическая динамика,, 2006. 480 с.

[6] Oniszczuk A., Wojtunik K.A. // Biomed Pharmacotherapy. 2016. V. 83. P. 912

[7] Voeikov V.L. // Reactive Oxygen Species, Water, Photons, and Life. 2010. V. 103. N 2-3. P. 321.

[8] Gudkov S.V., Bruskov V.I., Astashev M.E., Chernikov A.V., Yaguzhinsky L.S., Zakharov S.D. // J. Phys. Chem. 2011. V. 115. P. 7693.
[9] Belovolova L.V., Glushkov M.V., Vinogradov E.A. // Biophysics. 2014. V. 59. N 4. P. 524.

[10] Wagner J.R., Ali H., Langlois R., Brasseur N., van Lier J.E. // Photochem. Photobiol.1987. V. 45. N 5. P. 587.

[11] Rossi E., Van de Vorst A., Jori G. // Photochem. Photobiol. 1981. V. 34. P. 447.

[12] Lion Y., Delmelle M., Van De Vorst // Nature Publish. Group. 1976. V. 263. P. 442.

[13] Wang Sh.Y., Jiao H. // J. Agric. Food Chem. 2000. V. 48. N 11. P. 5677.

[14] Jonson P.G., Bellnier D.A., Henderson B.W. // Photochem. Photobiol. 1993. V. 57. P. 50-58.

[15] Campbell A.K. // Principles and Applications in Biology and Medicine. 1988. P. 608.

[16] Aksenova N.A., Zhientaev T. M., Brilkina A.A. et al. // Photonics \& Lasers in Medicine. 2013. V. 2. N 3. P. 189.

[17] Po Chun Pengs, Ruey Long Hong, Yi Jane Tsai, Pei Tzu Li, Tsuimin Tsai, Chin Tin Chen // Lasers Surg. Med. 2015. V. 47. N 1. P. 77.

[18] Бахшиев Н.Г. Спектроскопия межмолекулярных взаимодействий. Л., 1972. С. 263

[19] Васильев Р.Ф., Цаплев Ю.Б. // Успехи химии. 2006. Т. 75. C. 1103.

[20] Belovolova L.V., Glushkov M.V., Vinogradov E.A., Babintsev V.A., Golovanov V.I. // Phys. Wave Phenom. 2009. V. 17. N 1. P. 21.

[21] Fridovich I. // Med. Princ. Pract. 2013. V. 22. P. 131. doi $10.1159 / 000339212$ 